\title{
Variación sintáctica y diatópica con los verbos disfrutar y gozar
}

\author{
Syntactic and diatopic variation of verbs \\ disfrutar and gozar
}

\author{
BLANCA ELENA SANZ MARTIN \\ CHANTAL MELIS
}

\begin{abstract}
Universidad Autónoma de Aguascalientes. México. blancasanz27@hotmail.com
Universidad Nacional Autónoma de México. Correo electrónico: cme@unam.mx
\end{abstract}

Entre los verbos de régimen preposicional del español están incluidos algunos que, según los estudiosos, alternan libremente la construcción directa y la preposicional sin cambio de sentido. Los verbos psicológicos disfrutar y gozar se citan a menudo para ilustrar estos casos (disfrutar o gozar de la vida / disfrutar o gozar la vida). En el presente trabajo, analizamos el comportamiento de disfrutar y gozar en datos de uso provenientes de seis países hispanohablantes y encontramos que la variación entre patrones sintácticos que manifiestan estos verbos no es tan "libre" como suele afirmarse. Específicamente, establecimos que la elección de una construcción sobre otra está parcialmente gobernada por diferencias en el perfil de las unidades léxicas en cuestión, por la relación de los tipos de complemento con determinados matices de significado y por tendencias, inesperadas pero muy claras, de carácter diatópico. Estas tendencias dejan vislumbrar un proceso de intransitivización (régimen preposicional) que afecta a disfrutar y gozar en grados variables según los países.

Palabras clave: español, régimen preposicional, transitividad, variación diatópica, verbos psicológicos, variación diatópica.

Among the Spanish verbs held to govern a prepositional phrase as their complement there are some which, according to scholars, alternate freely between a prepositional object and a direct object with no change in meaning. The psychological verbs disfrutar (to enjoy) and gozar (to enjoy) are often cited to illustrate such cases (disfrutar or gozar de la vida 'to enjoy life'/ disfrutar or gozar la vida 'to enjoy life'). In the present work, we analyze the use of disfrutar and gozar in actual language data proceeding from six Spanish-speaking countries and we find that the variation between syntactic patterns allowed by these verbs is not as 'free' as it is claimed. Specifically, we establish that the choices of one constructional variant over the other are partly determined by differences in the respective profile of the lexical items in question, by the way in which the two types of complement correlate 
with particular shades of meaning, and by a set of unexpected but robust tendencies of diatopic character. These tendencies bring to view a process of detransitivization (prepositional coding) which affects disfrutar and gozar in variable degrees depending on the country.

Key words: diatopic variation, oblique (prepositional) case, psychological verbs, Spanish, transitivity

\section{INTRODUCCIÓN}

\subsection{El complemento preposicional}

Como es sabido, el fenómeno de "rección" preposicional en español (carecer de, aspirar a, consistir en, abogar por, etc.) ha hecho correr mucha tinta. En términos generales, los complementos que lo manifiestan se caracterizan por la relación semántica muy estrecha que contraen con el verbo -son o parecen ser elementos nucleares que funcionan de manera análoga a como lo hacen los complementos directos- pero ofrecen la peculiaridad de ir introducidos por una preposición, la cual, desde el punto de vista formal, los aproxima a los adyacentes circunstanciales que no están previstos en la valencia verbal y aportan contenidos marginales a la estructura de la oración.

La constatación del carácter dual de estos complementos llevó a Emilio Alarcos Llorach a proponer una nueva función gramatical, denominada "suplemento" (1970) u “objeto preposicional" (1994), que hacía oposición al complemento directo, por un lado, y al complemento circunstancial, por el otro. Dicha propuesta se erigió en punto de partida para una diversidad de publicaciones en las que se siguió ahondando en las propiedades inherentes del complemento preposicional (CP de aquí en adelante) y en la identificación de los verbos en espańol que obedecen a la definición del régimen preposicional (Bosque 1983; Cano Aguilar 1981; Fernández Fernández 1991; Gutiérrez Araus 1987; Gutiérrez Ordóñez 1997; Hernández Alonso 1990; Martínez Álvarez 1994; Martínez García 1986; Porto Dapena 1987; Rojo Sánchez 1990; entre otros). ${ }^{1}$

Una mirada a la bibliografía sobre este tema revela que los argumentos en favor del CP han girado en torno a demostrar la nuclearidad del sintagma en cuestión (para una visión de conjunto de las pruebas aducidas, véase Serradilla Cataño 1991-98) y han ido de la mano con cierta insistencia en la naturaleza "vacía" de la preposición que lo introduce, frente a las preposiciones cargadas de sentido o "plenas" que acompañan a los circunstanciales. De este modo, la preposición de régimen adquiere los rasgos de una marca transparente o incolora, ${ }^{2}$

\footnotetext{
${ }^{1}$ Cabe señalar que en los mencionados trabajos varían las posturas respecto a la nueva función sintáctica y sus delimitaciones. Tampoco faltan los gramáticos que oponen resistencia a su creación, por ejemplo, González Calvo (1994).

${ }^{2}$ Con respecto al significado que aporta la preposición, Barrajón López (2014) defiende la idea de que su caracterización debe partir de una perspectiva no discreta, en tanto que las preposiciones presentan diferentes
} 
desde el punto de vista semántico, cuyo oficio se limita a indicar la relación sintáctica que liga el complemento al verbo (Cano Aguilar 1981; Gutiérrez Araus 1987; Martínez García 1986; Rojo Sánchez 1990). ${ }^{3}$

Y así las cosas, no parece haber obstáculo para concluir que, en el fondo, el CD (complemento directo) y el CP son simples variantes morfológicas de una misma función gramatical, esto es, una misma relación "transitiva", la cual típicamente se formaliza de manera "directa" pero otras veces impulsa un fenómeno de "transitividad preposicional" (Cano Aguilar 1981; Santiago Guervós 2007, Hernández Alonso [1984] 1986). ${ }^{4}$ Para apoyar esta tesis, los autores resaltan las analogías significativas existentes entre frases como apoderarse de una ciudad y conquistar una ciudad (Cano Aguilar 1981: 36I), así como el hecho de que algunos verbos alternan libremente $\mathrm{CD}$ y CP: discutir (de) un asunto, cuidar (de) las vacas, sin provocar cambio ni en el significado del verbo ni en la relación de este con el complemento (Cano Aguilar 1981: 362).

\subsection{La heterogeneidad de los verbos preposicionales}

Sin embargo, independientemente de si se maneja el CP como variante morfológica de la relación transitiva o bien se conserva la idea de una función distinta e inconfundible con el CD, es evidente que la alternancia entre formas de complementación que admiten algunos verbos plantean una dificultad para el concepto de rección. En principio, uno esperaría construcciones fijas, de un tipo u otro, que fuesen "exigidas" por los respectivos lexemas verbales. Pero no es el caso. De hecho, el panorama arrojado por los llamados verbos preposicionales dista mucho de ser homogéneo, imponiéndose el reconocimiento de que "el grado de rección varía de unos verbos a otros" (Martínez García 1986: 61).

Algunos verbos preposicionales se comportan de acuerdo con lo esperado en la medida en que requieren la presencia de un objeto, enlazado por medio de una preposición única y no conmutable por otra (consistir en, equivaler a, versar sobre, etc.). ${ }^{5}$ En esta relación de interdependencia y mutua solidaridad descansa la definición del complemento preposicional canónico (Martínez García 1986).

grados de motivación semántica establecidos a partir de su proximidad o lejanía con respecto a su significado prototípico.

${ }^{3}$ Para los procesos de desemantización involucrados en la génesis de las preposiciones de régimen, véase Cano Aguilar (1984) y Martínez López (2001).

${ }^{4}$ La hipótesis de la transitividad preposicional se ha desarrollado igualmente dentro del marco de la Gramática Generativa; véanse Demonte (1991) y Hernanz y Brucart (1987). No obstante, en opinión de Soto Andión (2011), esta hipótesis pasa por alto las divergencias en el comportamiento sintáctico (pronominalización, conversión a pasiva, etc.) y semántico (afectación del objeto, valores aspectuales, etc.) que separan el CD del CP.

5 También hay casos de verbos regidos por dos preposiciones. Se trata de lo que Candalija Reina (2013) denomina doble complemento circunstancial. Algunos de los ejemplos que ofrece el autor son los siguientes: $E l$ padre advirtió a su hijo del peligro, Pilar coincide con Sara en todos sus gustos, Sara differe de Lidia en el estilo de sus vestidos (Candalija Reina 2013: 182) 
Otros verbos preposicionales, en cambio, son susceptibles de empleos "absolutos" en los que el complemento no se explicita, sin que por ello el verbo pierda su capacidad de significar (abusar, discrepar, insistir, etc.). La eliminación del elemento regido no pone en tela de juicio su nuclearidad, pues lo mismo ocurre con los complementos directos (Rojo Sánchez 1990), aunque sí, a juicio de algunos gramáticos, hace imposible sostener la tesis de que la preposición constituye el rasgo distintivo de los verbos en discusión (Gutiérrez Ordóñez 1997; Hernández Alonso 1990).

Después están los verbos, ya mencionados, que alternan la construcción directa y la preposicional. Como ya dijimos, estos verbos se aprovechan para realzar la similitud funcional de los tipos de estructura, pero al mismo tiempo introducen un elemento de variabilidad que oscurece o difumina el concepto de "rección" preposicional. De ahí, los intentos para demostrar que si un verbo presenta esta alternancia suele haber un cambio de contenido en el significado verbal: Atiende la casa ('cuídala') frente a Atiende a lo que te digan ('escucha'); Te confío el libro ('te lo presto') frente a ¿Confías en este libro? (¿tienes confianza en él?) (Martínez García 1986: 75), o bien intervienen diferencias en la categoría del complemento: dudar \{de algolen hacer algo\}; aprender \{la lecciónla leer (Cano Aguilar 1999: 1815).

Los casos residuales son aquellos en los que el cambio de una construcción a otra no está sujeto a restricciones combinatorias ni supone una alteración significativa en el verbo: cumple (con) tu deber, dudo (de) que vengan pronto (Martínez García 1986: 78); necesita ayuda / necesita de ayuda, cuida las flores / cuida de las flores (Martínez García 1995: 405). La existencia de estas alternancias se justifica apelando al hecho de que, siendo las preposiciones puras marcas de ligamiento sintáctico, pueden desaparecer sin problema porque la supresión de la forma vacía no afecta el sentido del enunciado (Martínez García 1986: 78; Cano Aguilar 1999: 1815). ${ }^{6}$

Para quienes otorgan importancia a divergencias en el plano de la forma, por el contrario, la alternancia entre CD y CP implica maneras distintas de concebir la situación comunicada. En esta perspectiva, la preposición distancia el complemento del verbo, de modo que el CP, en comparación con el CD, se presenta como más autónomo o menos integrado en el proceso verbal (García-Miguel 1995; Morera 1988; Trujillo 1988). En otras palabras, la preposición aporta un rasgo de contenido que influye en la interpretación semántica de la relación que el objeto entabla con el verbo.

Finalmente, tenemos los verbos que pueden construirse con dos o más preposiciones, habilidad que no se compagina bien con el planteamiento de la forma única y fija que opera como criterio para la identificación de la "rección" preposicional (Gutiérrez Ordóñez 1997). En este caso, se admite que la sustitución de una preposición por otra

\footnotetext{
${ }^{6}$ Cano Aguilar (1999: 1815) puntualiza al respecto que el argumento vale si la preposición no presenta sentido alguno, añadiendo que en ello radica una dificultad innegable ya que "no siempre puede afirmarse que la preposición carece por completo de sentido". Demonte (1991), por su parte, relaciona la variación formal con una diferencia de índole aspectual: la oración de transitividad directa se centra en el resultado télico de la acción, mientras que en la construcción preposicional se sitúa en primer plano un proceso atélico.
} 
evoca el comportamiento de las preposiciones "plenas" que introducen a los adyacentes circunstanciales. Estas son conmutables en un mismo entorno sintáctico e indican por lo tanto que contienen cierto semantismo propio (Martínez García 1986: 84). Pero el riesgo de confusión es sólo aparente ya que, como se señala, en la mayoría de los casos las distintas preposiciones vienen impuestas por la categoría semántica o lingüística del sintagma nominal: trataron de huir / trataron con los delincuentes; hablan sobre la politica actual I hablan de que no tienen tiempo; no dudé en huir de alli I dudaba de sus palabras (Martínez García 1986: 84, 153).

En la opinión de otros autores, sin embargo, la posibilidad de sustituir una preposición por otra muestra que incluso en sus usos parcialmente desemantizados dichas formas conservan matices de significado que se proyectan sobre las construcciones en que se insertan (García-Miguel 1995; Morera 1988).

A modo de conclusión, podría proponerse que el comportamiento heterogéneo de los verbos preposicionales hace manifiesta la necesidad de renunciar a la noción de las categorías discretas en beneficio de otro tipo de acercamiento, con un enfoque en la continuidad de los fenómenos lingüísticos, caracterizados por deslizamientos graduales de un dominio a otro, extensiones a partir de determinados núcleos prototípicos y límites borrosos entre categorías (Barrajón 2006; Barrio 2005-2006; Moure 1996).

\subsection{Los verbos disfrutar y gozar}

Por ahora, el punto de interés reside en que los cuasi-sinónimos disfrutar y gozar -objeto del presente estudio- figuran de manera prominente en las discusiones sobre los verbos preposicionales. Se les menciona, en particular, para ilustrar la alternancia entre régimen directo y régimen preposicional sin cambio de significado que admiten algunas unidades verbales: Gozan de tan larga vida como la propia filosofía / Hay que gozar la vida (Cano Aguilar 1981: 379); ellos disfrutaron (de) la herencia (Martínez García 1986: 78); disfrutaba la casa I disfrutaba de la casa (Martínez García 1995: 405); La ciudad de México ha disfrutado de paz y tranquilidad en el aspecto laboral (...) Ha gozado la capital de paz y tranquilidad frente a Disfruta este día, y gózalo hasta el final (Cano Aguilar 1999: 1824).

Desde un punto de vista sincrónico, la alternancia origina comentarios que empujan en direcciones opuestas: en un caso, se atribuye a disfrutar una tendencia hacia el régimen directo (Martínez García 1986: 7); en el otro, se hace hincapié en la predominancia del uso preposicional con ambos verbos (Cano Aguilar 1999: 1825). Históricamente, por otra parte, llama la atención el señalamiento de Cuervo, en su Diccionario de construcción y régimen de la lengua castellana, según el cual la preposición de que acompaña a disfrutar en algunos contextos vino a establecerse "por analogía con gozar" (Candalija Reina 2006: 520). Lo cierto es que gozar debió comenzar a regir de desde épocas tempranas, dado que una alusión al esquema preposicional de gozar ya se encuentra en la Gramática de la lengua castellana de Nebrija ([1492] 1989: 219): gozo me de tus cosas. 
Más allá de la libre alternancia entre CD y CP que subrayan los estudiosos respecto a disfrutar y gozar, encontramos que el segundo verbo también se elige para ejemplificar los casos en que la conmutación de una preposición por otra implica una diferencia en la categoría del complemento: goza de buena salud / goza en mortificarnos / goza con que todo el mundo lo admire (Martínez García 1995: 407; ver Martínez García 1986: 153).

Un estudio más detenido de disfrutar y gozar se ofrece en García-Miguel (1995: 114116). Según este autor, para quien las diferencias de expresión se relacionan con diferencias de contenido, los esquemas alternativos de estos verbos están en parte gobernados por el contraste semántico que opone un valor dinámico de "afección psico-física" a una acepción estativa de "posesión". García-Miguel observa, por ejemplo, que la situación dinámica alterna entre CD, de y a veces con (gozando ese mundo, disfrutando allá del buen sol, disfrutar con el espectáculo), mientras que la estativa sólo acoge de (Flora Miguel gozaba de una cierta condición floral). También sugiere que en la construcción directa se percibe un mayor grado de voluntariedad por parte del sujeto que entraña una diferencia en el grado de afección potencial del objeto.

Nuestro objetivo en el presente trabajo es ahondar en el comportamiento de disfrutar y gozar mediante un estudio pormenorizado de datos de uso. El trabajo se planteó en su inicio como una tentativa para verificar tres hipótesis derivadas de la bibliografía antecedente. En primer lugar, postulamos que disfrutar y gozar no tenían por qué funcionar de manera idéntica, lo cual se comprobó al establecerse la mayor transitividad de disfrutar-entendida como su mayor propensión a construirse con un CD- frente a gozar. Segundo, inferimos de las lecturas que podían existir diferencias entre países y optamos por una investigación de corte diatópico. ${ }^{7}$ Esta decisión nos ayudó a desvelar un continuum de transitividad en el que las seis variantes examinadas ocupan distintas posiciones. Por último, con la idea de que disfrutar y gozar no significaban necesariamente lo mismo en todos los contextos de uso, nos dimos a la tarea de profundizar en las acepciones de los dos verbos, acepciones que recogen los diccionarios y que nos permitieron arrojar luz sobre la interacción entre sintaxis y semántica en las construcciones analizadas.

\section{VARIACIÓN CONSTRUCCIONAL}

El estudio de disfrutar y gozar que presentamos a continuación está basado en una muestra de datos de uso, correspondientes a seis países hispanohablantes: Argentina, Colombia, Cuba, España, México y Perú. Utilizamos la base electrónica Corpus del Español del Siglo XXI de la Real Academia Española (CORPES) y extrajimos ejemplos de lengua escrita, centrándonos en la categoría "novela" del género "ficción". Nuestra intención era obtener 300 ejemplos para cada verbo en cada país. En algunos casos, la recolección de

\footnotetext{
${ }^{7}$ La necesidad de explicar la alternancia de régimen en términos dialectales se encuentra esbozada en el trabajo de Sanz y Eslava (2017: 43-4), donde se analiza la alternancia en los verbos disfrutar, necesitar y cuidar.
} 
datos se completó con materiales de las últimas décadas del siglo $\mathrm{XX}$ tomados de la base Corpus de Referencia del Español Actual (CREA) y en otros, hubo que contentarse con totales inferiores a la suma de 300 ocurrencias.

El primer resultado arrojado por los datos es que disfrutar y gozar comparten con otros verbos preposicionales (ver supra, $\$ 1.2$ ) la posibilidad de emplearse de manera "absoluta", es decir, sin complemento, lo cual sucede con cierta frecuencia en el uso, como en estos ejemplos:

(1) a. ¡Si hubieras visto como disfrutaba! Sentía que mi cuerpo por fin recibía su merecido, su merecido por ti y por mí (Cuba, Pantoja, El hijo, 2002, CorPES).

b. Por esos ańos nadie lo criticaba a uno por nada. Sólo nos ocupábamos de reír, actuar y gozar. Pero me gustaba la Economía y la ropa cara y la buena vida (Argentina, Sietecase, Pendejos, 2007, CORPEs).

Ambos verbos, en su acepción básica, expresan la noción de 'sentir placer. ${ }^{8}$ Este significado los vincula al campo semántico de los verbos de afección psíquica o verbos psicológicos, que suelen construirse con dos participantes: el ser humano (o animado) que percibe la emoción o el sentimiento referido, conocido como "experimentante", y la entidad (persona, cosa o situación) en relación con la cual el proceso interno toma lugar en el experimentante. En este trabajo, siguiendo a otros autores (Blansitt 1978; Dowty 1991; Talmy 1985), le asignamos al segundo participante la función semántica de "estímulo".

Con los verbos disfrutar y gozar, el experimentante se desempeña como sujeto de la oración, mientras que el estímulo lo designa el CD o CP que acompaña al verbo. Cuando los dos argumentos están presentes, disfrutar y gozar significan 'sentir placer por algo'. En los ejemplos de (1), en cambio, el estímulo no se codifica sintácticamente. Se hace referencia a una experiencia de placer sin especificar el elemento que la provoca o induce.

Obsérvese, sin embargo, que muchas de las construcciones sin complemento llevan un gerundio que funciona como predicado secundario opcional orientado al sujeto. En estos casos, el predicado secundario con gerundio expresa el estímulo de la sensación placentera9?:

\footnotetext{
${ }^{8}$ Ver 'Sentir alegría o placer en cierto sitio o con cierta cosa' (DUE 1998, s.v. disfrutar); 'Gozar, sentir placer' (DRAE 1992, s.v. disfrutar); 'Sentir alegría o placer por algo, en algún lugar o con alguna cosa’ (DEUM 1996, s.v. disfrutar). 'Experimentar gozo o placer' (DUE 1998, s.v. gozar); 'Sentir placer, experimentar suaves y gratas emociones' (DRAE 1992, s.v. gozar); 'Sentir gusto o placer' (DEUM 1996, s.v. gozar).

${ }^{9}$ Ocasionalmente, el estímulo toma la forma de una subordinada adverbial, como en los siguientes ejemplos:

(i) Se le nota que disfruta cuando están juntos, tienen muchas cosas en común, la misma pasión por el trabajo en la editorial, la afición a la lectura. (España. Tena, Tenemos que vernos, 2003, CORPEs)

(ii) Y sin embargo, no se regocija; un soldado no goza al matar enemigos, simplemente cumple con su deber (México, Toscana, El ejército iluminado, 2007, CORPEs)
} 
(2) a. Cuando llegaron los dos policías, tenía los perros sueltos por el jardín y disfrutó viendo cómo Villamuera y el otro permanecían un rato en el coche, con los cristales subidos, y aguardando como dos pasmarotes a que bajara a rescatarlos (España, Rojo, Matar para vivir, 2002, corpes).

b. Era bonito ver cómo gozaba regalándonos su país y sus costumbres (México, Lavín, Despertar los apetitos, 2008, corpes).

Algunas veces, y en particular con gozar, la construcción absoluta se utiliza para evocar el conjunto de experiencias positivas que conforman la esencia de la vida humana junto a otras experiencias de carácter negativo. En estos casos, gozar se coordina a menudo con sufrir:

(3) Y ese único hombre es el que nace, vive, goza, sufre y muere (España, Papell, El sol sobre la nieve, 2008, CORPES).

Además, por lo que a gozar se refiere, contamos con un uso absoluto que alude específicamente al placer experimentado en el acto sexual, como en (4):

(4) a. y al final nos la llevaremos a la cama y le enseñaremos a gozar (Colombia, Mendoza, Buda Blues, 2011, CORPEs).

b. Mientras él la embiste con violencia, ella no logra abandonarse al placer y gozar como en otras ocasiones (Perú, Bayly, La mujer de mi hermano, 2002, CORPES).

c. Gocé...- continuó ella-. La verdad es que cogimos bárbaro... (Argentina, Nielsen, Auschwitz, 2004, CORPES).

El enlace estrecho de gozar con el placer sexual es una propiedad semántica que opone este verbo a disfrutar, que no la tiene, y sobre la que volveremos más adelante. Por lo pronto, cabe observar que los contextuales sexuales cubren una porción no desdeńable de los empleos absolutos de gozar ${ }^{10}$ y pueden explicar la tendencia que manifiesta este verbo a prescindir del complemento estímulo con mayor frecuencia que disfrutar.

Dicha tendencia se aprecia en los datos cuantitativos recogidos en los Cuadros 1 (disfrutar) y 2 (gozar). Los números indican que, globalmente, los ejemplos absolutos representan el $24 \%$ del total de usos de gozar, frente al 13\% documentado para disfrutar. Al lado de los empleos absolutos, mostramos en los Cuadros 1 y 2 la distribución entre complementos directos (CD) y complementos preposicionales (CP) con disfrutar y gozar, respectivamente. En este primer acercamiento al comportamiento sintáctico de los verbos,

\footnotetext{
${ }^{10}$ Nuestra apreciación se sustenta en los siguientes datos cuantitativos, que muestran para cada país la relación entre el número de ejemplos sexuales y el total de los usos absolutos documentados con gozar: Argentina 24/65 (=37\%), Colombia 19/65 (=29\%), Cuba 30/61 (49\%), España 21/44 (= 48\%), México 14/48 (29\%), Perú 40/94 (43\%).
} 
se advierte que, en términos globales, disfrutar tiende a propiciar el régimen directo $(37 \%)$ más que gozar (20\%). Esta tendencia se mantiene en todos los países, si bien con divergencias porcentuales muy claras, las cuales dejan entrever un continuum de transitividad en el que México y España ocupan los polos opuestos: México favorece la construcción directa (60\% de CD con disfrutar, $41 \%$ de CD con gozar), mientras que España se inclina por el uso preposicional (61\% de CP con disfrutar, $76 \%$ de CP con gozar).

Cuadro 1. Distribución de las construcciones de disfrutar

\begin{tabular}{|l|c|c|c|c|c|c|c|}
\hline DISFRUTAR & \multicolumn{2}{|c|}{ Sin complemento } & \multicolumn{2}{|c|}{ CD } & \multicolumn{2}{|c|}{ CP } & Total \\
\hline ARGENTINA & 38 & $\mathbf{1 3 \%}$ & 96 & $\mathbf{3 2 \%}$ & 166 & $\mathbf{5 5 \%}$ & 300 \\
\hline COLOMBIA & 31 & $\mathbf{1 0 \%}$ & 126 & $\mathbf{4 2 \%}$ & 143 & $\mathbf{4 8 \%}$ & 300 \\
\hline CUBA & 39 & $\mathbf{1 7 \%}$ & 89 & $\mathbf{4 0 \%}$ & 97 & $\mathbf{4 3 \%}$ & 225 \\
\hline ESPAÑA & 68 & $\mathbf{2 3 \%}$ & 50 & $\mathbf{1 6 \%}$ & 182 & $\mathbf{6 1 \%}$ & 300 \\
\hline MÉXICO & 17 & $\mathbf{5 \%}$ & 179 & $\mathbf{6 0 \%}$ & 104 & $\mathbf{3 5 \%}$ & 300 \\
\hline PERÚ & 25 & $\mathbf{1 4 \%}$ & 54 & $\mathbf{2 9} \%$ & 105 & $\mathbf{5 7 \%}$ & 184 \\
\hline Global & 218 & $\mathbf{1 3 \%}$ & 594 & $\mathbf{3 7 \%}$ & 797 & $\mathbf{5 0 \%}$ & 1609 \\
\hline
\end{tabular}

Cuadro 2. Distribución de las construcciones de gozar

\begin{tabular}{|c|c|c|c|c|c|c|c|}
\hline $\boldsymbol{G O Z A R}$ & \multicolumn{2}{|c|}{ Sin complemento } & \multicolumn{2}{|c|}{ CD } & \multicolumn{2}{|c|}{ CP } & Total \\
\hline ARGENTINA & 65 & $\mathbf{2 2 \%}$ & 48 & $\mathbf{1 6 \%}$ & 180 & $\mathbf{6 2 \%}$ & 293 \\
\hline COLOMBIA & 65 & $\mathbf{2 3 \%}$ & 54 & $\mathbf{2 0 \%}$ & 156 & $\mathbf{5 7 \%}$ & 275 \\
\hline CUBA & 61 & $\mathbf{3 2 \%}$ & 43 & $\mathbf{2 2 \%}$ & 90 & $\mathbf{4 6 \%}$ & 194 \\
\hline ESPANAA & 44 & $\mathbf{1 5 \%}$ & 29 & $\mathbf{9 \%}$ & 227 & $\mathbf{7 6 \%}$ & 300 \\
\hline MÉXICO & 48 & $\mathbf{1 6 \%}$ & 122 & $\mathbf{4 1 \%}$ & 130 & $\mathbf{4 3 \%}$ & 300 \\
\hline PERÚ & 94 & $\mathbf{4 3 \%}$ & 18 & $\mathbf{8 \%}$ & 108 & $\mathbf{4 9 \%}$ & 220 \\
\hline Global & 377 & $\mathbf{2 4 \%}$ & 314 & $\mathbf{2 0} \%$ & 891 & $\mathbf{5 6 \%}$ & 1582 \\
\hline
\end{tabular}




\section{Caracterización SEMÁNTICA}

Hemos adelantado que las variantes sintácticas de disfrutar y gozar se correlacionan con diferencias semánticas. Cuando disfrutar y gozar aparecen sin complemento (ver supra, \$2), actualizan únicamente el significado de 'sentir placer', pero en sus usos con complemento pueden expresar otro sentido, que lleva una idea de posesión y se glosa en el presente trabajo como 'tener algo provechoso'.

En los diccionarios, encontramos las siguientes definiciones, a veces escindidas en dos acepciones: 'Tener cierta cosa buena' (DUE 1998, s.v. disfrutar), 'Tener cierta cosa útil, beneficiosa o agradable' (DUE 1998, s.v. gozar); 'Tener alguna condición buena física o moral, o gozar de comodidad, regalo o conveniencia' y 'Tener el favor o amistad de alguno' (DRAE 1992, s.v. disfrutar), 'Tener y poseer algo útil y agradable' y 'Tener alguna buena condición física o moral' (DRAE 1992, s.v. gozar); 'Tener alguien alguna cosa buena, cómoda o conveniente' y 'Recibir alguien el provecho de algo, la protección o la amistad de alguien' (DEUM 1996, s.v. disfrutar), 'Tener alguien algo que le es útil o provechoso' (DEUM 1996, s.v. gozar).

El sentido de posesión se ilustra con ejemplos tales como: gozar o disfrutar de buena salud o de fama, gozar de la libertad, disfrutar del favor del jefe, y motiva el señalamiento de que normalmente requiere la preposición $d e$.

Dicho sentido implica un proceso de desemantización. Se diluye la referencia a una 'sensación' placentera para dar paso a la idea más abstracta o menos experiencial de 'contar con' algo útil o agradable. No obstante, se conserva el matiz de algo que es evaluado positivamente, tal como se valora el placer, y aquí está el puente por el que se transita del significado psíquico a la relación de posesión.

Ahora bien, contrariamente a lo que sugieren los diccionarios, donde se nos da a entender que disfrutar y gozar muestran la misma propensión o facilidad para actualizar el sentido posesivo en cuestión, nuestros datos ponen en evidencia una diferencia notable entre gozar, que se utiliza a menudo con este significado, y disfrutar, que lo expresa de manera mucho más esporádica (ver infra, los Cuadros 3 y 4).

Merece la pena señalar al respecto que nuestros datos encuentran eco en el Diccionario combinatorio del español contemporáneo (REDES) dirigido por Ignacio Bosque (2004). Bajo la entrada de gozar, en efecto, esta obra proporciona una nutrida lista de sustantivos que, al combinarse con el verbo, disparan el sentido de 'contar con'. Entre ellos están incluidos sustantivos que hacen referencia a lugares en alguna jerarquía social (estatus, rango...), que tienen que ver con reconocimiento social (popularidad, fama ...), autoridad, hegemonía o liderazgo (poder, influencia...) o ventajas sobre los demás (favor, privilegio...), que designan la condición de poseer diversos méritos (talento, inteligencia...), atracción natural $\mathrm{u}$ otros rasgos de personalidad (encanto, carisma...), o bien comunican estados de homogeneidad o estabilidad (bienestar, tranquilidad...), entre otros. En el caso de disfrutar, por contraste, REDES no hace mención alguna de este tipo de colocaciones ni del sentido de 'contar con'. Resta decir que nos apoyamos en las categorías semánticas identificadas en 
dicho diccionario para separar los usos posesivos de disfrutar y gozar, en nuestros datos, de aquellos en los que los verbos mantenían el significado de 'sentir placer'.

En (5) ofrecemos ejemplos que denotan la sensación de placer:

(5) a. La multitud, ajena a su angustia presidencial, disfrutaba el frenesí del baile (Argentina, Maronna y Pescetti, Copyright: plagios literarios y poder politico al desnudo, 2001, CORPES).

b. La pareja disfrutaba del paseo haciéndose arrumacos (Argentina, Tena, Tenemos que vernos, 2003, CORPES).

c. Cómo goza la comida, en especial los platillos que le recuerdan a Grecia Muerde, mastica, bebe [...] (México, Popper, Los abuelos, 2009, corpes)

d. Luego están los que se sientan a gozar de esa cascada de luz que viene del cielo (Cuba, Miguel Muñoz, Vida Mía, 2006, corpes).

y en (6) ilustramos el desliz semántico hacia la posesión de algo bueno, provechoso o conveniente:

(6) a. Pero mi desarraigo es mi privilegio. Disfruto de las ventajas del extranjero. Fluctúo de un mundo a otro (España, Torres, Hombre de lluvia, 2004, CORPES).

b. Esta gente siempre ha gozado de un enorme poder (España, Corral, El códice del peregrino, 2012, CORPES).

c. No lo dudo, Bernardo. Usted nos ha acompañado desde hace tantos años que goza de mi más absoluta confianza (Colombia, Restrepo, Lo que nunca se sabrá, 2011, CORPES).

d. Cioran, el que murió de Alzheimer, gozó de la lucidez casi toda su vida (México, Prieto, Campo de batalla, 2008, CORPES). ${ }^{\text {II }}$

Cabe observar que cuando disfrutar y gozar se emplean en la segunda acepción admiten con libertad sujetos inanimados, como en (7), en vista de que también las cosas pueden concebirse como entidades que están en posesión de algo provechoso: ${ }^{12}$

(7) a. calentaba el agua, y empezaba a fluir delicadamente, las ramas de eucalipto verde, [...] luego cuando la tina disfrutaba de una tibieza angelical la

\footnotetext{
11 Tenemos en nuestro corpus un par de ejemplos con gozar que ilustran un proceso de desemantización consumado, en la medida en que el sentido de 'posesión' se extiende a objetos que no llevan ya ningún matiz de valoración positiva o placentera: gozaba de una reputación siniestra (Cuba, González-Llorente, La confesión del Comandante y otras historias, 2006, CORPEs); gozaba de una excepcional miopia (España, Mendoza, La aventura del tocador de señoras, 2001, CORPES).

12 En su estudio sobre disfrutar y gozar, García-Miguel (1995: 115) también advierte que el valor estativo de 'posesión' que a veces manifiestan estos verbos contrasta con el sentido psíquico en admitir sujetos inanimados.
} 
despertaban suavemente (Colombia, Rubiano, El anarquista jubilado, 2001, CORPES).

b. Las puestas de sol en ese balneario chileno, que gozan de justa fama, alcanzan su máximo esplendor en la pequeña bahía que se abre justo frente a la casa amarilla (Argentina, Martínez, El vuelo de la reina, 2003, corpes)

c. llevando en los bolsillos, a manera de muestras, pequeñas barras de oro, de no más de trescientos gramos, que gozaban de aceptación inmediata (Perú, Guzmán, La ciudad de los sueños perdidos, 2004, CORPEs).

En cambio, la descripción de una experiencia de placer exige que el sujeto designe a una persona (o ser animado) capaz de 'sentir' gusto o deleite. En los poquísimos casos en que aparece un sujeto inanimado con este significado, el referente evoca metonímicamente a una persona (8a) o se percibe una intención estilística de personificación (8b):

(8) a. El principio de una comezón amorosa al voltear y verla sola. Pureza amada que mis ojos nunca llegaron a gozar (Perú, Trelles Paz, El círculo de los escritores asesinos, 2004, CORPES).

b. Si bien las llantas delanteras están en todo momento sobre la arena, las posteriores están enterradas hasta la mitad, si no más, en la espesa orilla, como si la arena estuviera disfrutando de comerse semejantes pedazos de caucho y relamiéndose por el fierro que tarde o temprano degustaría (Perú, Neyra, Tsunami, 2012, CORPES).

Ahora bien, es preciso añadir que el verbo gozar, a diferencia de disfrutar, abarca una tercera acepción, definida en los diccionarios como 'poseer sexualmente a una mujer' (DUE 1998, s.v. gozar, ver 'conocer carnalmente a una mujer': DRAE 1992, s.v. gozar) o, en términos menos restringidos, como 'poseer sexualmente a una persona' (DEUM 1996, s.v. gozar). En nuestro corpus, documentamos este significado con complementos femeninos (9a) y masculinos (9b), en oraciones recíprocas (9c) y en construcciones donde el valor sexual se actualiza por medio de una referencia al cuerpo de la persona a la que se 'posee' (9d):

(9) a. Jesús no solo gozó de Conchita, sino que pasó por la cama de una buena parte de las amigas de la mujer que le adoctrinaron en sus artes (Espańa, Viejo, La memoria del agua, 2009, CORPES).

b. Pero ella manejaba sus propias reglas: escogió y tuvo los mejores muchachos, jóvenes y mayores; fue la dueña de todos los bailes y gozó los parejos más apetecibles, arrinconándolos hasta el final de las fiestas (Colombia, Posada, Alicia y las maravillas, 2009, CORPES).

c. Lino siguió siendo pésimo amante durante los veinticinco ańos que compartieron cama, menos en esas escasas ocasiones en las que pudieron gozarse sin 
tapujos (Cuba, Alberto, Esther en alguna parte o El romance de Lino y Larry Po, 2005, CORPES).

d. cada noche me sentía como un presidiario que no ha gozado el cuerpo de una mujer en muchos años (México, Aridjis, La zona del silencio, 2005, CORPES).

En los Cuadros 3 (disfrutar) y 4 (gozar) enseñamos la distribución respectiva de los significados que pueden llevar los dos verbos cuando se construyen con un complemento. Los datos cuantitativos muestran que el significado dominante en los dos verbos es el de 'sentir placer', pero lo es mucho más en el caso de disfrutar, pues supera en 31 puntos porcentuales a gozar. Nótese que en los seis países la distribución es muy similar, salvo España, donde los porcentajes varían más significativamente con respecto al resto de los dialectos, sobre todo con disfrutar.

Asimismo, los datos de los cuadros 3 y 4 confirman que la acepción 'tener algo provechoso' es globalmente menos frecuente con disfrutar (9\%) que con gozar (32\%). Como también se aprecia, las ocurrencias del sentido posesivo alcanzan un porcentaje particularmente alto en el dialecto peninsular (46\%), y más adelante ahondaremos en la importancia de este resultado.

Cuadro 3. Panorama semántico de disfrutar en construcciones con complemento

\begin{tabular}{|l|c|c|c|c|c|}
\hline DISFRUTAR & \multicolumn{2}{|c|}{ 'sentir placer' } & \multicolumn{2}{c|}{ 'tener algo provechoso' } & Total \\
\hline ARGENTINA & 239 & $\mathbf{9 1 \%}$ & 23 & $\mathbf{9 \%}$ & 262 \\
\hline COLOMBIA & 240 & $\mathbf{8 9} \%$ & 29 & $\mathbf{1 1 \%}$ & 269 \\
\hline CUBA & 170 & $\mathbf{9 1} \%$ & 16 & $\mathbf{9 \%}$ & 186 \\
\hline ESPANAA & 205 & $\mathbf{8 8} \%$ & 27 & $\mathbf{1 2 \%}$ & 232 \\
\hline MÉXICO & 269 & $\mathbf{9 5} \%$ & 14 & $\mathbf{5 \%}$ & 283 \\
\hline PERÚ & 137 & $\mathbf{8 6} \%$ & 22 & $\mathbf{1 4 \%}$ & 159 \\
\hline Global & 1260 & $\mathbf{9 1} \%$ & 131 & $\mathbf{9 \%}$ & 1391 \\
\hline
\end{tabular}


Cuadro 4. Panorama semántico de gozar en construcciones con complemento

\begin{tabular}{|c|c|c|c|c|c|c|c|}
\hline GOZAR & \multicolumn{2}{|c|}{ 'sentir placer' } & \multicolumn{2}{|c|}{$\begin{array}{c}\text { 'poseer sexualmente } \\
\text { a una persona' }\end{array}$} & \multicolumn{2}{|c|}{$\begin{array}{l}\text { 'tener algo } \\
\text { provechoso' }\end{array}$} & Total \\
\hline ARGENTINA & 148 & $65 \%$ & 9 & $4 \%$ & 71 & $31 \%$ & 228 \\
\hline COLOMBIA & 125 & $60 \%$ & 21 & $10 \%$ & 64 & $30 \%$ & 210 \\
\hline CUBA & 87 & $65 \%$ & 18 & $14 \%$ & 28 & $21 \%$ & 133 \\
\hline ESPAÑA & 114 & $45 \%$ & 22 & $9 \%$ & 120 & $46 \%$ & 256 \\
\hline MÉXICO & 165 & $65 \%$ & 18 & $7 \%$ & 69 & $28 \%$ & 252 \\
\hline PERÚ & 81 & $64 \%$ & 11 & $9 \%$ & 34 & $27 \%$ & 126 \\
\hline Global & 720 & $60 \%$ & 99 & $8 \%$ & 386 & $32 \%$ & 1205 \\
\hline
\end{tabular}

\section{LA ALTERNANCIA DE RÉGIMEN DE ACUERDO CON LOS DISTINTOS SIGNIFICADOS DE DISFRUTAR Y GOZAR}

\subsection{Alternancia de régimen con el significado 'tener algo provechoso' en gozar y disfrutar}

Mencionamos arriba que los diccionarios resaltan el hecho de que disfrutar y gozar, en su acepción 'tener algo provechoso', tienden a regir la preposición de. La regularidad con la que el sentido posesivo favorece el CP se verifica en nuestros datos, donde predomina netamente el uso preposicional -con porcentajes que oscilan entre $81 \%$ y $100 \%$ - y donde la preposición empleada es generalmente de, como en (10):

(10) a. Por esas coincidencias en las que da gusto fijarse, fue igualmente criada en una familia con seis hijos; si bien su hogar había disfrutado de una posición algo más cómoda que la de Jonás (Argentina, Neuman, Una vez Argentina, 2003, CORPES).

b. Se educaría en el colegio de San Gabriel, gozaría de todos los privilegios de su clase y se iniciaría en los caminos que su padre había escogido para él (España, Ruiz Zafón, La sombra del viento, 2003, CORPEs).

c. Ludo siguió bebiendo sin saber por qué ese millionario gozaba en ese bar de maleantes de tanta impunidad (Perú, Ribeyro, Los geniecillos dominicales, 1983, CREA).

Ocasionalmente, el sentido posesivo se realiza en una construcción de régimen directo, como las de (11). Esto sucede un poco más con disfrutar (10\%) que con gozar (4\%). Según podemos apreciar en los ejemplos de (11), el CD raras veces se presenta bajo 
la forma de una frase léxica; se trata a menudo de un pronombre relativo que propicia la omisión de la preposición:

(11) a. Hay que ser capo como Anselmo, para disfrutar los privilegios del esmoquin gris: bolsillos abiertos, paseos por el casino y recreos en Los Alcaravanes (Colombia, Méndez, Malena, 2003, corpes).

b. las magníficas condiciones que disfrutaban los reclusos en las cárceles españolas (España, Del Val, Estamos dentro, 2010, corpes).

c. Candela despertó en la familia una aprobación muy superior a la que gozaba mi tío (Argentina, Lojo, Árbol de familia, 2010, CORPES).

El panorama de la distribución entre CD y CP con el significado 'tener algo provechoso' está resumido en el Cuadro 5 (disfrutar y gozar). En este caso, destaca el comportamiento bastante homogéneo que presentan los distintos dialectos. En todas las regiones, la acepción posesiva de disfrutar y gozar hace esperar la presencia de un complemento introducido por $d e$.

Cuadro 5. Régimen preposicional (de) con el significado posesivo

\begin{tabular}{|c|c|c|c|c|c|c|c|c|}
\hline \multicolumn{9}{|c|}{ 'tener algo provechoso' } \\
\hline & \multicolumn{4}{|c|}{ GOZAR } & \multicolumn{4}{|c|}{ DISFRUTAR } \\
\hline ARGENTINA & 3 & 68 & $96 \%$ & 71 & 1 & 26 & $96 \%$ & 27 \\
\hline COLOMBIA & 4 & 60 & $94 \%$ & 64 & 4 & 25 & $86 \%$ & 29 \\
\hline CUBA & 0 & 28 & $100 \%$ & 28 & 3 & 13 & $81 \%$ & 16 \\
\hline ESPAÑA & 2 & 118 & $98 \%$ & 120 & 1 & 26 & $96 \%$ & 27 \\
\hline MÉXICO & 5 & 64 & $93 \%$ & 69 & 2 & 12 & $86 \%$ & 14 \\
\hline PERÚ & 0 & 34 & $100 \%$ & 34 & 3 & 19 & $86 \%$ & 22 \\
\hline Global & 14 & 372 & $96 \%$ & 386 & 14 & 121 & $90 \%$ & 135 \\
\hline
\end{tabular}




\subsection{Alternancia de régimen con el significado 'sentir placer' en gozar y disfrutar}

En esta sección analizamos las construcciones en las que disfrutar y gozar significan 'sentir placer', al igual que en sus usos absolutos (ver supra, \$2), pero con la diferencia de que aquí llevan el complemento que remite al estímulo del proceso psíquico experimentado por el sujeto. Sirvan de ilustración estos ejemplos:

(12) a. Ha comprado la comida y las bebidas preguntándose qué le gustará más a Gonzalo, cómo disfrutará mejor la cena, qué cosas le harán feliz al comer (Perú, Bayly, La mujer de mi hermano, 2002, CORPEs).

b. Álvaro y Felipe disfrutaban de sendas cervezas frías (Cuba, Álvarez, Naufragios, 2002, CORPES).

c. Mejor no le contará nada: se casará simplemente con ella, compartirán todo, volverán a comenzar: serán socios del mismo club, leerán los mismos libros, disfrutarán con las mismas películas (Argentina, Obligado, Salsa, 2002, CORPES).

d. Todos lo adoraban, gozaban sus chistes, sus ocurrencias afortunadas (México, Prieto, Campo de batalla, 2008, CORPES).

e. No quiere pensar en nada, sólo en gozar de esta paz inesperada (Espańa, García Montalvo, Retrato de dos hermanas, 2004, CORPes).

f. Con la barbilla levantada, la pose de una reina, ella goza_on la imagen de su cuerpo en el espejo (Argentina, Martínez, El vuelo de la reina, 2002, CORPES).

g. Llegó a costarle trabajo decidir con quién iría a pasear cada tarde, tanto gozaba en estas escapadas que le molestaba la impertinencia de la monja que le anunciaba el fin del castigo (Cuba, García Martín, Nunca podré olvidarte, 2003, CORPES). ${ }^{13}$

La variación en la formalización del complemento estímulo que reflejan estos ejemplos contrasta con el empleo más o menos fijo de la preposición de que se vio asociado al sentido posesivo de disfrutar y gozar (ver supra, \$4): hay alternancias entre CD y CP, y este, a su vez, puede construirse con distintas preposiciones. En el ámbito de la sensación placentera, como se mostrará enseguida, adquieren visibilidad divergencias llamativas en el eje diatópico, junto con una oposición palpable en el grado de transitividad de los dos verbos.

\footnotetext{
${ }^{13}$ Vale la pena señalar que la asociación de gozar con el ámbito del sexo sigue manifestándose en los empleos bi-argumentales que ahora nos ocupan, como en estos ejemplos:

(i) Dina logró su primer orgasmo de aquella sesión. Yo, por respeto a sus años, aguanté el mío y me vine luego que ella había terminado de gozar plenamente el suyo (Perú, Mariátegui, La virtud de Alexandra, 2003, CORPES).

(ii) lamenté haber soltado su puta lengua: gracias a ella no volverá a gozar del sabor de las tetas que tanto le gustan (Colombia, Enríquez, ¡Bum! o la trágica relatividad de Koltès, 2008, CORPEs).
} 
En los Cuadros 6 (disfrutar) y 7 (gozar) están recogidos los datos de distribución entre CD y CP. Destaca, en primer lugar, la mayor propensión de disfrutar a motivar el régimen directo (46\%) en comparación con gozar (26\%). A nuestro juicio, esta diferencia sugiere que el arraigo del sentido posesivo que caracteriza a gozar ha propiciado la extensión analógica de una preposición al dominio semántico de la experiencia de placer.

Cuadro 6. Alternancia de régimen con el significado psíquico 'sentir placer'

\begin{tabular}{|c|c|c|c|c|c|}
\hline \multicolumn{6}{|c|}{ DISFRUTAR } \\
\hline & \multicolumn{2}{|c|}{$\mathrm{CD}$} & \multicolumn{2}{|c|}{$\mathrm{CP}$} & Total \\
\hline ARGENTINA & 95 & $40 \%$ & 144 & $60 \%$ & 239 \\
\hline COLOMBIA & 122 & $51 \%$ & 118 & $49 \%$ & 240 \\
\hline CUBA & 86 & $51 \%$ & 84 & $49 \%$ & 170 \\
\hline ESPAÑA & 49 & $24 \%$ & 156 & $76 \%$ & 205 \\
\hline MÉXICO & 177 & $66 \%$ & 92 & $34 \%$ & 269 \\
\hline PERÚ & 51 & $37 \%$ & 83 & $63 \%$ & 134 \\
\hline Global & 580 & $46 \%$ & 677 & $54 \%$ & 1257 \\
\hline
\end{tabular}

Cuadro 7. Alternancia de régimen con el significado psíquico 'sentir placer'

\begin{tabular}{|l|c|c|c|c|c|}
\hline \multicolumn{7}{|c|}{ DISFRUTAR } \\
\hline & \multicolumn{2}{|c|}{ CD } & \multicolumn{2}{c|}{ CP } & Total \\
\hline ARGENTINA & 48 & $\mathbf{2 1 \%}$ & 180 & $\mathbf{7 9 \%}$ & 228 \\
\hline COLOMBIA & 54 & $\mathbf{2 6 \%}$ & 156 & $\mathbf{7 4 \%}$ & 210 \\
\hline CUBA & 43 & $\mathbf{3 2} \%$ & 90 & $\mathbf{6 8 \%}$ & 133 \\
\hline ESPANA & 29 & $\mathbf{1 1 \%}$ & 227 & $\mathbf{8 9} \%$ & 256 \\
\hline MÉXICO & 122 & $\mathbf{4 8} \%$ & 130 & $\mathbf{5 2 \%}$ & 252 \\
\hline PERÚ & 18 & $\mathbf{1 4 \%}$ & 108 & $\mathbf{8 6} \%$ & 126 \\
\hline Global & 314 & $\mathbf{2 6} \%$ & 891 & $\mathbf{7 4 \%}$ & 1205 \\
\hline
\end{tabular}


Centrándonos ahora en los seis dialectos, tenemos resultados variables que se despliegan a lo largo de un continuum de transitividad. Para ambos verbos, México arroja el porcentaje más alto de construcciones directas ( $66 \%$ con disfrutar, $48 \%$ con gozar), frente a España, cuyo CD exhibe los índices de frecuencia más bajos (24\% con disfrutar, $11 \%$ con gozar). Las demás regiones están situadas entre estos dos extremos, con Colombia y Cuba manteniéndose un poco más cerca del polo de alta transitividad, seguidos de Argentina y luego Perú, que tienden a inclinarse hacia el polo de baja transitividad.

Examinada la alternancia entre CD y CP, podemos enfocarnos en la elección de preposiciones con el CP. Arriba, en (12), ofrecimos algunos ejemplos de la variación preposicional y en (13) añadimos unos cuantos más:

(13) a. Un día lo vimos saltar del tejado a la terraza, en la que nos encontrábamos, para disfrutar de la primavera que empezaba (España, Díaz, Amor en Florencia, 2002, CORPES).

b. No te goces de la ruina de tu enemigo; no se alegre tu corazón al verle sucumbir (Perú, Goldemberg, El nombre del padre, 2001, CORPES). ${ }^{\text {I4 }}$

c. Yo tenía que ir allá, a disfrutar igual que siempre, con el tiro de pichón, las tómbolas, el laberinto (España, Ruiz, Obertura francesa, 2002, CORPEs)

d. Gozaba con saber cómo el pintor Carlos Enríquez le había birlado una mujer al pendejo de Carpentier (Cuba, Suri Quesada, El instrumento de Changó, 2004, CORPES).

e. ¿Qué mujer amaría un amor prohibido y desafiaría las leyes de los dioses mortales que gozan en el poder? (Colombia, Torres, Guanentyba. Hijo del Sol, 2013, CORPES)

En realidad, la variación es menor de lo que podría parecer a primera vista. Los datos cuantitativos recogidos en el Cuadro 8 ponen de manifiesto, efectivamente, que de predomina con ambos verbos y en todos los países. El significado 'sentir placer' tiene la preferencia por de en común con el sentido posesivo que analizamos en la sección anterior. Sin embargo, a diferencia del último, admite otras opciones -en y principalmente con- que compiten de forma mucho más notable con de.

\footnotetext{
${ }^{14}$ En el ejemplo (13b) gozar va acompañado del incremento pronominal te. Estos casos son poco frecuentes en el corpus (documentamos un total de 15 ocurrencias pronominales, de las cuales la mitad procede de los datos colombianos). Generalmente, el uso de gozarse lo propician, bien las estructuras donde el verbo se combina con la preposición en (i), o bien los contextos en los que el verbo actualiza el significado de 'poseer sexualmente a una persona' (ii):

[i] Mirtha se gozó en su victoria y, en defensa del decoro y el buen gusto, apoyó la mano sobre el colchón de pelos del brazo de Fracassi (Argentina, Guebel, Carrera y Fracassi, 2004, CORPes).

[ii] ¿Y si en vez de robar nos gozamos esas nenas?, insinué cuando salimos de la tienda (Colombia, Álvarez, 35 muertos, 2011, CORPES).
} 
Cuadro 8. Variación de preposiciones con el significado psíquico 'sentir placer'

\begin{tabular}{|c|c|c|c|c|c|c|c|c|c|c|c|c|c|}
\hline & \multicolumn{6}{|c|}{ DISFRUTAR } & \multicolumn{7}{|c|}{$G O Z A R$} \\
\hline & \multicolumn{2}{|c|}{ de } & \multicolumn{2}{|c|}{ con } & \multirow{2}{*}{$\frac{e n}{0}$} & \multirow{2}{*}{$\frac{\text { Total }}{144}$} & \multicolumn{2}{|c|}{ de } & \multicolumn{2}{|c|}{ con } & \multicolumn{2}{|c|}{$e n$} & Total \\
\hline ARGENTINA & 137 & $95 \%$ & 7 & $5 \%$ & & & 90 & $85 \%$ & 15 & $14 \%$ & 1 & $1 \%$ & 106 \\
\hline COLOMBIA & 115 & $97 \%$ & 3 & $3 \%$ & 0 & 118 & 68 & $78 \%$ & 17 & $20 \%$ & 2 & $2 \%$ & 87 \\
\hline CUBA & 73 & $87 \%$ & 11 & $13 \%$ & 0 & 84 & 39 & $72 \%$ & 13 & $24 \%$ & 2 & $4 \%$ & 54 \\
\hline ESPAÑA & 132 & $85 \%$ & 24 & $15 \%$ & 0 & 156 & 82 & $87 \%$ & 11 & $12 \%$ & 1 & $1 \%$ & 94 \\
\hline MÉXICO & 88 & $96 \%$ & 4 & $4 \%$ & 0 & 92 & 51 & $85 \%$ & 9 & $15 \%$ & 0 & $0 \%$ & 60 \\
\hline PERÚ & 85 & $99 \%$ & 1 & $1 \%$ & 0 & 86 & 47 & $69 \%$ & 21 & $31 \%$ & 0 & $0 \%$ & 68 \\
\hline Global & 630 & $93 \%$ & 50 & $7 \%$ & 0 & 680 & 377 & $80 \%$ & 86 & $18 \%$ & 6 & $1 \%$ & 469 \\
\hline
\end{tabular}

En algunos estudios, cuyos autores rechazan la tesis de las preposiciones "vacías" (ver supra, \$1.1), la alternancia delcon es objeto de unos breves comentarios, observándose al respecto que de, con su valor de 'origen' o 'causa', ayuda a visualizar el complemento estímulo como la entidad que provoca la sensación de placer (Candalija Reina 2006: 525, 657; García-Miguel 1995: 115), mientras que con orienta la lectura hacia un escenario de acción conjunta (Candalija Reina 2006: 526) o un papel de tipo instrumental (GarcíaMiguel 1995: 115).

Lo que llama la atención en nuestros datos es que la probabilidad de que aparezca con aumenta con gozar, especialmente en algunos países (Colombia, Cuba, Perú), y queremos proponer que esta situación no es del todo accidental. Tomando en cuenta la especialización de gozar en la expresión del sentido posesivo, junto con la regularidad de la preposición de en estos contextos (ver supra, \$4), hay motivos para postular que en algunas regiones los hablantes utilizan con, en lugar de $d e$, con el fin de oponer la sensación placentera a la relación de posesión y asimismo realzar la frontera existente entre las dos acepciones del verbo gozar.

\subsection{Alternancia de régimen con el significado sexual en gozar}

Como se recordará, gozar cuenta con una tercera acepción, 'poseer sexualmente a una persona', que no tiene disfrutar. Del Cuadro 4 presentado arriba se desprendió que se trata de un uso menor. No obstante, dicho significado ofrece cierto interés ya que conforma el bastión de resistencia del CD. Los ejemplos de régimen directo son de este tipo:

(14) a. Relájate, olvídate de todo, déjate ir, goza a la ruca, está bien buena, así vas a durar mucho más tiempo en venirte (México, Agustín Ramírez, Vida con mi viuda, 2004, CORPES). 
b. El médico Machuca respiró hondo y prendió satisfecho un cigarro cuando acabó de gozarla (España, Royuela, La pasión según las fieras, 2003, CORPES).

Según muestra el Cuadro 9, la tendencia a construir gozar con un CD cuando significa 'poseer sexualmente a una persona' es notablemente más alta (49\%) que la registrada en los contextos donde el verbo indica 'sentir placer' (26\%; ver supra, Cuadro 7). De nueva cuenta, las distintas regiones se dejan organizar a lo largo de un continuum de transitividad, que va de México (67\% de CD) a España (32\% de CD), con los demás países colocados en posiciones intermedias (Colombia $>$ Cuba $>$ Perú $>$ Argentina), pero en todos los casos el índice de frecuencia del CD es superior al que arrojan los usos de 'sentir placer'.

Cuadro 9. Alternancia de régimen con el significado propio de gozar ('poseer sexualmente a una persona')

\begin{tabular}{|l|c|c|c|c|c|}
\hline \multicolumn{5}{|c|}{ GOZAR } \\
\hline & \multicolumn{2}{|c|}{ CD } & \multicolumn{2}{c|}{ CP } & Total \\
\hline ARGENTINA & 3 & $\mathbf{3 3 \%}$ & 6 & $\mathbf{6 7 \%}$ & 9 \\
\hline COLOMBIA & 12 & $\mathbf{5 7 \%}$ & 9 & $\mathbf{4 3} \%$ & 21 \\
\hline CUBA & 10 & $\mathbf{5 6} \%$ & 8 & $\mathbf{4 4 \%}$ & 18 \\
\hline ESPAÑA & 7 & $\mathbf{3 2} \%$ & 15 & $\mathbf{6 8} \%$ & 22 \\
\hline MÉXICO & 12 & $\mathbf{6 7 \%}$ & 6 & $\mathbf{3 3} \%$ & 18 \\
\hline PERÚ & 5 & $\mathbf{4 5 \%}$ & 6 & $\mathbf{5 5 \%}$ & 11 \\
\hline Global & 49 & $\mathbf{4 9} \%$ & 50 & $\mathbf{5 1 \%}$ & 99 \\
\hline
\end{tabular}

Adicionalmente, el significado sexual de gozar se distingue por propiciar la elección de la preposición con. Así, en estos ejemplos:

(15) a. Porque lo único que se me ocurre es invitar a Gonzalo a una playa exótica, muy lejos de acá, y gozar con él (Perú, Bayly, La mujer de mi hermano, 2002, CORPES).

b. Claro, sus putas eran de altura y gozó con las más elegantonas, tetonas y nalgonas (Cuba, García Martín, Nunca podré olvidarte, 2003, CORPES).

En términos globales, como vemos en el Cuadro 10, con alcanza el $41 \%$ del total de los usos de $\mathrm{CP}$ con el valor sexual, aunque en este caso median diferencias importantes 
entre hablas. Las regiones que favorecen la preposición -Colombia, Cuba y Perú- son las que también se perfilaban como más inclinadas hacia su empleo con el significado de 'sentir placer' (ver supra, Cuadro 8). Se confirma, pues, la tendencia de los hablantes de estas regiones a separar formalmente el sentido posesivo (de) de gozar de las dos acepciones ligadas a la noción de placer (competencia de/con). Nótese que en el caso de 'poseer sexualmente a una persona', la motivación para elegir con se justifica mejor aún: el complemento se refiere al ser humano que participa en el acto sexual, y con el uso de esta forma cobra fuerza un matiz de 'compañía' que viene a sobreponerse al escenario de control posesivo envuelto en la tercera acepción de gozar.

Cuadro 10. Alternancia de preposiciones con el significado sexual ('poseer sexualmente a una persona')

\begin{tabular}{|l|c|c|c|c|c|}
\hline \multicolumn{7}{|c|}{ GOZAR } \\
\hline & \multicolumn{2}{|c|}{ de } & \multicolumn{2}{c|}{ con } & Total \\
\hline ARGENTINA & 5 & $\mathbf{8 3} \%$ & 1 & $\mathbf{1 7 \%}$ & 6 \\
\hline COLOMBIA & 5 & $\mathbf{5 6 \%}$ & 4 & $\mathbf{4 4 \%}$ & 9 \\
\hline CUBA & 0 & $\mathbf{0 \%}$ & 8 & $\mathbf{1 0 0} \%$ & 8 \\
\hline ESPAÑA & 12 & $\mathbf{7 5 \%}$ & 4 & $\mathbf{2 5 \%}$ & 16 \\
\hline MÉXICO & 6 & $\mathbf{1 0 0} \%$ & 0 & $\mathbf{0 \%}$ & 6 \\
\hline PERÚ & 2 & $\mathbf{3 3 \%}$ & 4 & $\mathbf{6 7 \%}$ & 6 \\
\hline Global & 30 & $\mathbf{5 9 \%}$ & 21 & $\mathbf{4 1 \%}$ & 51 \\
\hline
\end{tabular}

\section{Proceso de intransitivización}

Resumiendo, hemos encontrado que disfrutar y gozar evidencian un panorama de intensa variación, a la vez caracterizado por ciertos patrones recurrentes de comportamiento. No cabe duda de que la zona de mayor regularidad la constituyen los ejemplos en los que los dos verbos actualizan el significado posesivo de 'tener algo provechoso'. Cuando esto ocurre, podemos predecir con un muy alto grado de probabilidad que el complemento requerido llevará la marca preposicional de, independientemente de si se trata de disfrutar o gozar y sin importar la procedencia geográfica de los usos. La regla opera con los dos verbos a lo ancho del territorio hispanohablante.

El punto en que se distancian disfrutar y gozar respecto a este significado tiene que ver con la frecuencia de su empleo. Al parecer, gozar se ha especializado para el valor posesivo en cuestión, de cuya expresión se encarga raramente disfrutar. Y una vez constatado 
este hecho, cobran sentido algunas de las tendencias observadas en nuestros datos. Por ejemplo, el que gozar, en todos los dialectos, funcione de forma más clara que disfrutar como verbo preposicional apunta a un proceso de extensión analógica desde el ámbito de la relación de posesión, que exige $d e$, a los contextos de sensación placentera, donde la preposición es opcional. Dicho proceso no ha alcanzado disfrutar en el mismo grado, dada la escasez de su empleo en la acepción posesiva, promoviéndose de este modo una situación de mayor estabilidad para el CD que explica la diferencia en el perfil de transitividad de los dos verbos (disfrutar > gozar).

La influencia del sentido posesivo sobre las pautas sintácticas registradas en nuestro corpus también se deja sentir en el terreno de los contrastes diatópicos. A lo largo de nuestro estudio, vimos que España se destaca por ser la región más favorable al CP en todos los contextos analizados. Y esto hay que poner en relación con la frecuencia, ostensiblemente más alta que en otros dialectos, con la que gozar se utiliza para expresar el valor posesivo en dicho país (ver supra, Cuadro 4). Los datos asimismo sugieren que a partir del núcleo preposicional, conformado por los usos posesivos de gozar, el CP se fue difundiendo y generalizando a todos los ámbitos de significación cubiertos por dos verbos semánticamente afines.

La consolidación del CP, que reflejan con mayor claridad los datos peninsulares, significa para los verbos involucrados un proceso de intransitivización. Como evidencia a favor de este proceso, podemos aducir el hecho de que los pocos complementos directos que aparecen en el dialecto peninsular son raras veces frases nominales. El CD toma la forma del clítico correferencial o bien corresponde a un pronombre relativo:

(16) a. Una persona que no concebía la noche sin disfrutarla (España, Díaz, Amor en Florencia, 2002, CORPes).

b. quizá él sea el Gran Turista, el Arquetipo, en el sentido de que el mundo le es permanentemente ofrecido, aunque no sabe gozarlo (Espańa, De Villena, La nave de los muchachos griegos, 2003, cORPEs).

c. Tuvo una visión, como en las películas que tanto disfrutaba: Aldaya le iba a servir a los demás en bandeja (Espańa, Ruiz Zafón, La sombra del viento, 2003, CORPES).

En otras palabras, los elementos que llenan la casilla del CD están categorialmente restringidos, y esto nos habla de una función que ya no tiene la capacidad de realizarse plenamente.

\section{Conclusiones}

En este trabajo, nos acercamos a dos verbos de régimen preposicional del español, definidos en la bibliografía como representantes de aquellos que alternan el complemento directo y el preposicional sin cambio notable en el significado. 
La pertenencia al grupo del que forman parte disfrutar y gozar implica una desviación con respecto al funcionamiento canónico de los verbos de régimen -unidades léxicas que exigen una preposición, fija y única, para la elaboración de una oración gramatical, pero es a la vez aprovechada por algunos estudiosos que tratan dicha alternancia como prueba de que el complemento directo y el complemento preposicional son dos manifestaciones morfológicas de una misma relación "transitiva".

La contribución del presente trabajo, apoyada en datos provenientes de seis países hispanohablantes, consiste en haber puesto al descubierto que el cambio de una construcción a otra con disfrutar y gozar obedece a diferencias en el plano léxico, semántico y geográfico. Específicamente, nuestro estudio de uso ayudó a establecer que ambos verbos se comportan como regulares verbos preposicionales cuando actualizan la acepción 'tener algo provechoso'. También demostró que en los contextos donde los verbos se utilizan para comunicar una sensación de placer -el ámbito real de la alternancia entre $\mathrm{CD}$ y $\mathrm{CP}-$, disfrutar está más propenso a construirse con un complemento directo que gozar. Por último, sacó a la luz un continuum diatópico de transitividad, el cual se extiende desde México, la región más favorable al complemento directo, hasta España, donde prevalece el complemento preposicional. Entre estos dos extremos están situados los demás países, con Colombia y Cuba manteniéndose un poco más cerca del polo de alta transitividad, seguidos de Argentina y Perú, que tienden a inclinarse hacia el polo de baja transitividad.

Según la hipótesis desarrollada en este trabajo, los tres resultados que acabamos de destacar deben verse como íntimamente entrelazados. En el centro de la relación que los une está el uso regularmente preposicional de gozar en su acepción posesiva 'tener algo provechoso'. Este significado lo tiene mucho más afianzado gozar en comparación con disfrutar y, además, lo favorecen los hablantes peninsulares con índices de frecuencia más altos que en cualquier otro país. Ambas observaciones son importantes, ya que permiten postular el camino de intransitivización por el que se ha ido extendiendo el régimen preposicional en esta pequeña parcela de la gramática del español.

El camino supone una fase de extensión, reflejada en todas las variantes del español, en la que la estrecha asociación de gozar con el valor posesivo ha propiciado que un empleo preposicional se difunda a los otros ámbitos de significación del verbo. El segundo paso en este camino lo perfilan los datos correspondientes a España, donde la proximidad semántica de los dos verbos parece haber dado pie a que el comportamiento de gozar se propague a disfrutar y envuelva a este en un proceso similar de intransitivización.

\section{Corpus}

Real Academia Española. Corpus de referencia del español actual (CREA). [http://corpus. rae.es]

Real Academia Española. Corpus del Español del siglo XXI (CORPES). [http://www.rae.es/ recursos/banco-de-datos/corpes-xxi] 


\section{Obras CitAdas}

Alarcos Llorach, Emilio. 1970. "Verbo transitivo, verbo intransitivo y estructura del predicado". Estudios de gramática funcional del español. Madrid: Gredos. 109-123.

Alarcos Llorach, Emilio. 1994. Gramática de la lengua española. Madrid: Espasa Calpe.

Barrajón López, Elisa. 2006. Análisis contrastivo locativo-nocional de la complementación de régimen verbal en el español hablado en Alicante: Usos espaciales y abstractos de salir $y$ entrar. Tesis doctoral. Universidad de Alicante.

Barrajón López, Elisa. 2014. "La función semántica del complemento preposicional nocional y local". Revista de Investigación Lingüistica 17: 11-30

Blansitt, Edward L. Jr. 1978. "Stimulus as a semantic role". En Abraham Werner (ed.), Valence, Semantic Case, and Grammatical Relations. Ámsterdam: John Benjamins, 311-324.

Bosque, Ignacio. 1983. "Dos notas sobre el concepto de suplemento". Dicenda 2: 147-156.

Bosque, Ignacio, dir. 2004. REDES. Diccionario combinatorio del español contemporáneo. Madrid: Ediciones SM.

Candalija Reina, José Antonio. 2006. Preposiciones vacías del español: complemento de régimen preposicional. Tesis doctoral. Universidad de Alicante.

Candalija Reina, José Antonio. 2013. “Transitividad preposicional: el doble complemento preposicional en español”. Revista de Investigación Lingüistica 16: 177-207.

Cano Aguilar, Rafael. 1981. Estructuras sintácticas transitivas en el español actual. Madrid: Gredos.

Cano Aguilar, Rafael. 1984. "Cambios de construcción verbal en español clásico". Boletín de la Real Academia Española 64: 203-255.

Cano Aguilar, Rafael. 1999. "Los complementos de régimen verbal". En Ignacio Bosque y Violeta Demonte (dirs.), Gramática descriptiva de la lengua española, vol. 2: Las construcciones sintácticas fundamentales. Relaciones temporales, aspectuales y modales. Madrid: Espasa Calpe. 1807-1854.

Cuervo, Rufino José. 1998. Diccionario de construcción y régimen de la lengua castellana. Madrid: Instituto Caro y Cuervo.

del Barrio, Florencio. 2005-2006. "Gradualidad y gramaticalización en el estudio del complemento preposicional”. Contextos 45-48: 283-301.

de Santiago Guervós, Javier. 2007. El complemento (de régimen) preposicional. Madrid: Arco Libros.

Demonte, Violeta. 1991. Detrás de la palabra. Estudios de gramática del español. Madrid: Alianza.

Dowty, David. 1991. "Thematic Proto-roles and Argument Selection”. Language 67: 547619.

Fernández Fernández, Antonio. 1991. "Sobre la diferenciación entre aditamentos y suplementos y sobre el 'complemento adverbial". Revista de Filología de la Universidad de la Laguna 10: 139-158. 
García-Miguel, José María. 1995. Transitividad y complementación preposicional en español. Santiago de Compostela: Universidade (Verba, anexo 40).

González Calvo, José Manuel. 1994. "Apreciaciones sobre la función sintáctica de suplemento". LEA 16.2: 175-191.

Gutiérrez Araus, María Luz. 1987. "Sobre transitividad preposicional en español”. Verba. 14: 367-381.

Gutiérrez Ordóńez, Salvador. 1997. “¿Hablamos del suplemento?”. En La oración y sus funciones. Madrid: Arco/Libros. 175-194.

Hernanz, Maria Lluïsa, y José María Brucart. 1987. La sintaxis 1. Principios teóricos. la oración simple. Barcelona: Crítica.

Hernández Alonso, César. 1990. "En torno al suplemento". Anuario de Letras 28: 5-25. Hernández Alonso, César. [1984] 1986. Gramática funcional del español. Madrid: Gredos.

Lara, Luis Fernando, dir. 1996. Diccionario del español usual en México. México: El Colegio de México. [Citado como DEUM].

Martínez Álvarez, Josefina. 1994. "La función de suplemento”. Español Actual 61: 59-67.

Martínez García, Hortensia. 1995. "Combinatoria y semántica de los verbos suplementarios". Revista Española de Lingüistica 25.2: 397-409. . 1986. El suplemento en español. Madrid: Gredos.

Martínez López, Juan A. 2001. "Sobre el complemento preposicional". Moenia 7: 199-260.

Moliner, María. 1998. Diccionario de uso del español. 2a ed. Madrid: Gredos. [Citado como DUE].

Morera, Marcial. 1988. Estructura semántica del sistema preposicional del español moderno y sus campos de uso. Puerto del Rosario: Cabildo Insular de Fuerteventura.

Moure, Teresa. 1996. La alternativa no-discreta en lingüistica. Una perspectiva histórica y metodológica. Universidad de Santiago de Compostela: Servicio de Publicaciones.

Nebrija, Antonio de. [1492] 1989. Gramática de la lengua castellana. Estudio y edición de Antonio Quilis. Madrid: Centro de Estudios Ramón Areces.

Porto Dapena, José-Álvaro. 1987. "Sobre el suplemento. Notas al hilo de una publicación reciente". Thesaurus 42.1: 122-136.

Real Academia Española. 1992. Diccionario de la lengua española. 22a ed. Madrid: Gredos. [Citado como DRAE].

Rojo Sánchez, Guillermo. 1990. "Sobre los complementos adverbiales". Jornadas de Filología. Homenaje a Francisco Marsá. Barcelona: Universitat de Barcelona: 153-171.

Sanz Martin, Blanca Elena y Eslava Heredia Crisina. 2017. "Disfrutar la vida o disfrutar de la vida. ¿La alternancia entre régimen directo y preposicional es un fenómeno de diátesis?”. Textos en proceso 3.1: 23-48.

Serradilla Castaño, Ana María. 1991-98. "El complemento de régimen preposicional: Criterios para su identificación”. Cauce. Revista de Filología y su Didáctica 20-21: 10171051.

Soto Andión, Xosé. 2011. "Notas sobre la complementación circunstancial y preposicional”. Lingüistica 26: 260-275. 
ESTUDIOS FILOLÓGICOS

Talmy, Leonard. 1985. "Lexicalization Patterns: Semantic Structure in Lexical Forms". En Timothy Shopen (ed), Language Typology and Syntactic Description, vol. 3: Grammatical Categories and the Lexicon. Cambridge: Cambridge University Press. 57-150 Trujillo, Ramón. 1988. Introducción- a la semántica española. Madrid: Arco/Libros. 